\title{
Searching for a New Balance \\ for the Eurozone Governance in the Aftermath of the Coronavirus Crisis
}

\author{
José Caetano, Paulo Ferreira, and Andreia Dionísio
}

\begin{abstract}
The economic crisis triggered by the coronavirus exposed the gaps in the European Monetary Union (EMU) governance, creating fears to repeat the sovereign debt crisis. In view of the magnitude of the crisis and the financial interdependence inside that union, strong policy coordination and central measures are crucial. The discussion on debt mutualisation continued to be based on clashing political positions. This chapter identifies the instability recorded in sovereign spreads at the beginning of the crisis and reviews the structural factors that caused it. We discuss the limited role of the ECB answer. So, the issue of Eurobonds is revisited, bringing new arguments since the EMU faces an exogenous shock. We sustain that the approval of the European Commission's original Next Generation EU programme on the European Council in July 21, could anchor a new governance model for the EMU, based on the principle of subsidiarity and the refusal of moral hazard arguments.
\end{abstract}

Keywords Eurozone governance $\cdot$ Monetary policy $\cdot$ Sovereign debts • Eurobonds $\cdot$ Moral hazard

\section{Introduction}

The sovereign debt crisis by 2009 left major marks on the European panorama and the Eurozone in particular. The crisis showed the structural divergences between the countries of the EMU. In particular, one of the relevant issues since then has been the sustainability of public debt in some member states. One answer to the sustainability

J. Caetano $\cdot$ A. Dionísio

CEFAGE, IIFA, Universidade de Évora, Évora, Portugal

e-mail: jcaetano@uevora.pt
A. Dionísio
e-mail: andreia@uevora.pt
P. Ferreira $(\bowtie)$

VALORIZA-Research Center for Endogenous Resource Valorization, Instituto Politécnico de Portalegre, Praça do Município, 11, 7300-110 Portalegre, Portugal

e-mail:pferreira@ipportalegre.pt 